\section{Korean Guidelines for Cardiopulmonary Resuscitation. Part 7. Pediatric advanced life support}

Yu Hyeon Choi ${ }^{1}$, Do Kyun Kim², Eun Kyeong Kang ${ }^{3}$, Jin-Tae Kim ${ }^{4}$, Jae Yoon $\mathrm{Na}^{5}$, Bobae Park ${ }^{6}$, Seok Ran Yeom ${ }^{7}$, Joo Suk $\mathrm{Oh}^{8}$, Jisook Lee ${ }^{9}$, Won Kyoung Jhang ${ }^{10}$, Soo In Jeong ${ }^{11}$, Jin Hee Jung ${ }^{12}$, Jea Yeon Choi ${ }^{13}$, June Dong Park', Sung Oh Hwang ${ }^{14}$; on behalf of the Steering Committee of 2020 Korean Guidelines for Cardiopulmonary Resuscitation and Emergency Cardiovascular Care

\footnotetext{
'Department of Pediatrics, Seoul National University College of Medicine, Seoul, Korea ${ }^{2}$ Department of Emergency Medicine, Seoul National University Hospital, Seoul, Korea ${ }^{3}$ Department of Pediatrics, Dongguk University Ilsan Hospital, Goyang, Korea

${ }^{4}$ Department of Anesthesiology and Pain Medicine, Seoul National University College of Medicine, Seoul, Korea

${ }^{5}$ Department of Pediatrics, Hanyang University Medical Center, Hanyang University College of Medicine, Seoul, Korea

${ }^{6}$ Department of Nursing, Seoul National University Hospital, Seoul, Korea

${ }^{7}$ Department of Emergency Medicine, Pusan National University College of Medicine, Busan, Korea

${ }^{8}$ Department of Emergency Medicine, The Catholic University of Korea College of Medicine, Seoul, Korea

${ }^{9}$ Department of Emergency Medicine, Ajou University College of Medicine, Suwon, Korea

${ }^{10}$ Department of Pediatrics, Children's Hospital, Asan Medical Center, Seoul, Korea

${ }^{11}$ Department of Pediatrics, Ajou University Hospital, Suwon, Korea

${ }^{12}$ Department of Emergency Medicine, SMG-SNU Boramae Medical Center, Seoul, Korea

${ }^{13}$ Department of Emergency Medicine, Gachon University Gil Medical Center, Gachon University College of Medicine, Incheon, Korea

${ }^{14}$ Department of Emergency Medicine, Yonsei University Wonju College of Medicine, Wonju, Korea
}

The 2020 Korean pediatric cardiopulmonary resuscitation (CPR) guidelines refer to the medical recommendations derived from the scientific evidence for pediatric advanced life support (PALS). These guidelines are based on the scientific consensus and treatment recommendations made in 2020 by the International Liaison Committee on Resuscitation, which establishes the CPR guideline. Studies published on PALS were considered in formulating it. ${ }^{1}$ Evidence for the revised items that is of high clinical importance and requires additional consideration was reviewed in an acceptable adaptation or hybrid format, and a meta-analysis or scoping review was done.

\section{MAJOR CHANGES IN THE 2020 PALS GUIDELINES}

When compared with the 2015 guideline, ${ }_{1}^{2}$ the changes in the 2020 PALS guidelines are as follows.

Defibrillation energy dose

The first defibrillator dose of $2 \mathrm{~J} / \mathrm{kg}$ is recommended for shockable rhythms in pediatric cardiac arrest (Class I, Level B-NR).
elSSN: 2383-4625

Received: 7 March 2021

Revised: 26 March 2021

Accepted: 28 March 2021

Correspondence to: June Dong Park Department of Pediatrics, Seoul National University College of Medicine, 101 Daehak-ro, Jongno-gu, Seoul 03080, Korea

E-mail:jdparkmd@snu.ac.kr ORCID

https://orcid.org/0000-0001-8113-1384

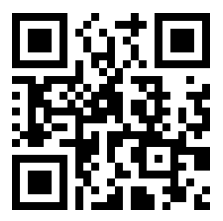

How to cite this article:

Choi YH, Kim DK, Kang EK, Kim JT, Na JY, Park B, Yeom SR, Oh JS, Lee J, Jhang WK, Jeong $\mathrm{SI}$, Jung JH, Choi JY, Park JD, Hwang SO; on behalf of the Steering Committee of 2020 Korean Guidelines for Cardiopulmonary Resuscitation and Emergency Cardiovascular Care. 2020 Korean Guidelines for Cardiopulmonary Resuscitation. Part 7. Pediatric advanced life support. Clin Exp Emerg Med 2021;8(S):S81-S95. https://doi. org/10.15441/ceem.21.027

This is an Open Access article distributed under the terms of the Creative Commons Attribution Non-Commercial License (https:// creativecommons.org/licenses/by-nc/4.0/). 


\section{Extracorporeal CPR}

In case of pediatric in-hospital cardiac arrest (IHCA) with no responsiveness to conventional $\mathrm{CPR}$, resuscitation using extracorporeal membrane oxygenation (ECMO) can be considered depending on the availability of resources in the hospital (Class Ilb, Level C-LD).

\section{Invasive hemodynamic monitoring}

It is vital to maintain adequate hemodynamics during CPR of infants or children; however, the usefulness of invasive hemodynamic monitoring for maintaining systolic and diastolic blood pressure during resuscitation is uncertain (Class Ilb, Level C-LD).

\section{Cardiac arrest due to myocarditis or dilated cardiomyopathy}

For children with impending or occurring cardiac arrest due to myocarditis or dilated cardiomyopathy, early transfer to a hospital where mechanical circulatory support, such as ECMO and ventricular assist device, is available should be considered (Class IIb, Level C-LD).

Factors predicting the outcomes during cardiac arrest In case of IHCA with non-shockable rhythm, epinephrine should be administered within 5 min after the initiation of chest compressions (Class I, Level C-LD).

Waveform capnography monitoring in pediatric IHCA may be considered for predicting a return of spontaneous circulation (ROSC) (Class Ilb, Level C-LD).

\section{Targeted temperature management post-cardiac arrest}

When performing targeted temperature management (TTM) in comatose pediatric patients after cardiac arrest, it is effective to set a target temperature of $32^{\circ} \mathrm{C}$ to $34^{\circ} \mathrm{C}$ or $36^{\circ} \mathrm{C}$ to $37.5^{\circ} \mathrm{C}$, and actively monitor the body temperature to prevent fever (Class Ila, Level C-LD).

\section{Oxygen and carbon dioxide targets after ROSC}

For children who achieve ROSC after CPR, it can be beneficial to measure the partial pressure of arterial oxygen and carbon dioxide $\left(\mathrm{CO}_{2}\right)$, and manage them with appropriate goals depending on their condition. In the absence of special consideration, it is reasonable to maintain normal levels of oxygen and $\mathrm{CO}_{2}$ (Class Ila, Level C-LD).

Factors predicting the prognosis after ROSC

For neurological prognosis after ROSC in children, it may be necessary to monitor the occurrence of convulsions, examine bioche- mical markers (neuron specific enolase, S100 protein, lactate, delta neutrophil index [DNI]), or perform diffusion-weighted magnetic resonance image (Class Illb, Level C-LD).

Blood pressure monitoring and DNI test can be useful to predict discharge and short-term survival in children who have ROSC after IHCA and out-of-hospital cardiac arrests (OHCA) (Class Ilb, Level C-LD).

\section{SEQUENCE OF PEDIATRIC ADVANCED LIFE SUPPORT}

PALS should be immediately performed following pediatric basic life support (PBLS), if possible. Figs. 1 and 2 show the algorithm for PALS. PBLS includes recognition of the patient with no response and breathing, activation of the emergency service system, checking the patient's pulse and respiration within $10 \mathrm{sec}-$ onds, and initiating CPR. High-quality CPR should be also performed in the same way as in PBLS-chest compressions depth of $1 / 3$ of chest wall thickness or $4 \mathrm{~cm}$ in infants and 4 to $5 \mathrm{~cm}$ in children, compression rate of 100-120/min, allowing complete chest recoil after each compression, avoiding excessive ventilation, and minimizing discontinuation of chest compression. The compression-ventilation ratios for 1 - and 2-rescuers are 30:2 and 15:2, respectively. If the advanced airway is secured, provides 1 breath every 6 seconds (about 10 breaths/min) regardless of compression. To prevent rescuer fatigue and decline in the quality of chest compressions, the role of rescuers can be switched every 2 minutes. An electrocardiogram (ECG) monitoring device or AED pads should be attached as early as possible. After analyzing the ECG rhythms, appropriate action must be taken.

During the coronavirus disease 2019 (COVID-19) pandemic, if cardiac arrest is confirmed, personal protective equipments should be used before CPR and the use of CPR devices, if available, should be considered (Fig. 3). CPR is initiated after confirming its necessity, thereby minimizing the number of participants receiving CPR. Personal protective equipment for airborne precautions should be worn during the aerosol-generating procedures (chest compressions, airway securing, and ventilation), and fluid-resistant surgical masks, eye protections, short-sleeved aprons, and gloves should be worn during defibrillation. After beginning CPR and analyzing ECG rhythms, defibrillation is performed once in cases of shockable rhythms, following endotracheal intubation. In cases of nonshockable rhythms, intubation is immediately performed after checking rhythms, following which CPR is continued. During endotracheal intubation, chest compressions are stopped, video laryngoscope is used if possible, and a ventilator with a filter is connected. When the intubation is delayed, the supraglottic airway 


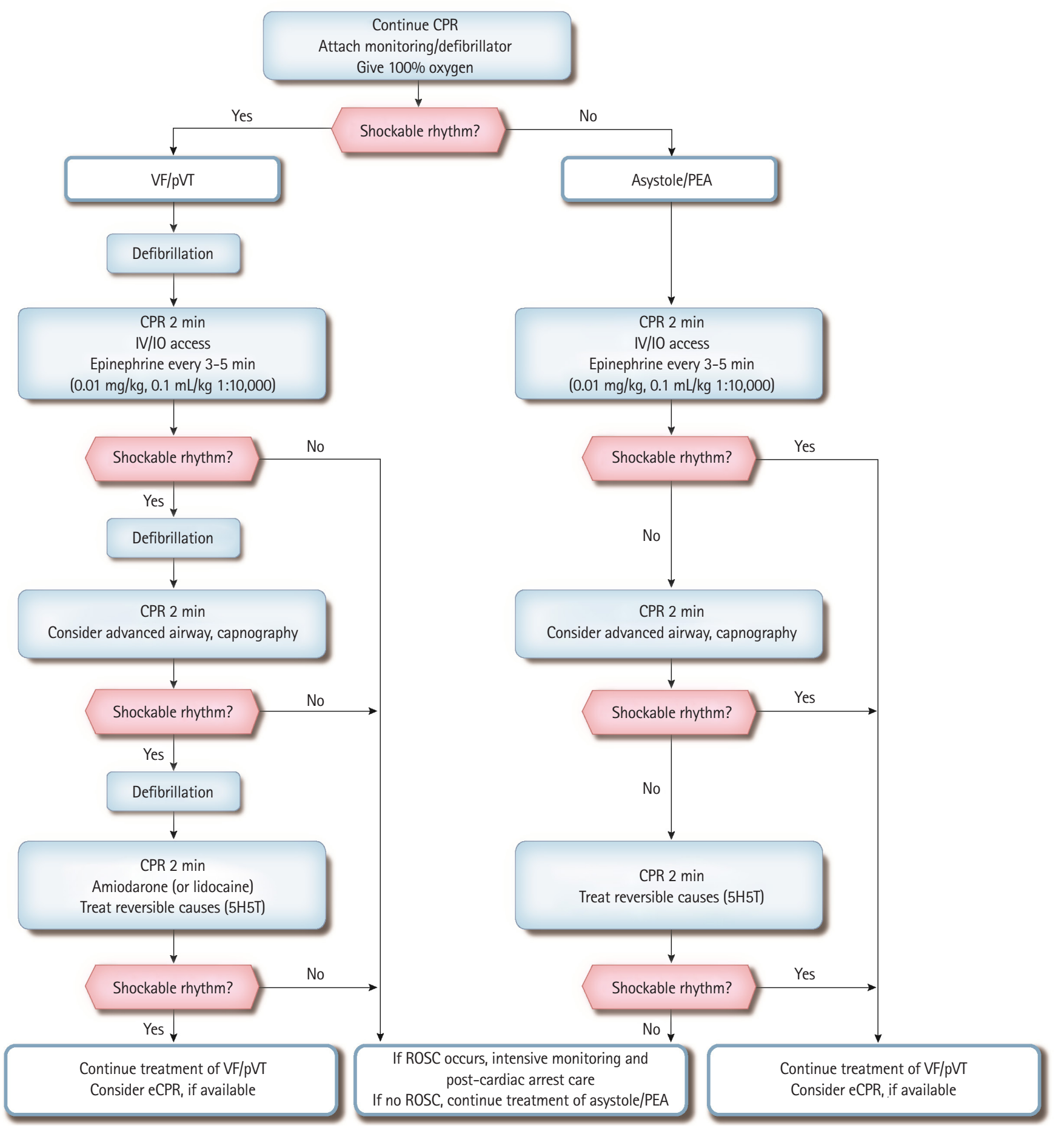

Fig. 1. Pediatric cardiac arrest algorithm for advanced life support team in the hospital. CPR, cardiopulmonary resuscitation; $V F$, ventricular fibrillation; pVT, pulseless ventricular tachycardia; PEA, pulseless electrical activity; IV, intravenous; IO, intraosseous; 5H, hypothermia, hypoxia, hypovolemia, hypokalemia/hyperkalemia, and hydrogen ion-acidosis; $5 \mathrm{~T}$, tamponade, thrombosis-pulmonary or cardiac, toxin, tension pneumothorax, and trauma; eCPR, extracorporeal CPR; ROSC, return of spontaneous circulation.

(SGA) is inserted or a bag-mask-ventilation with high-efficiency particulate absorbing filter is used. ${ }^{3}$ After CPR, the rescuers should wash their hands with soap and water as soon as possible or disinfect their hands with alcohol-based hand sanitizer in accor- dance with the infection control guidelines; moreover, it is recommended to change clothes. In addition, local health authorities should be contacted to check for COVID-19 testing and self-isolation. 


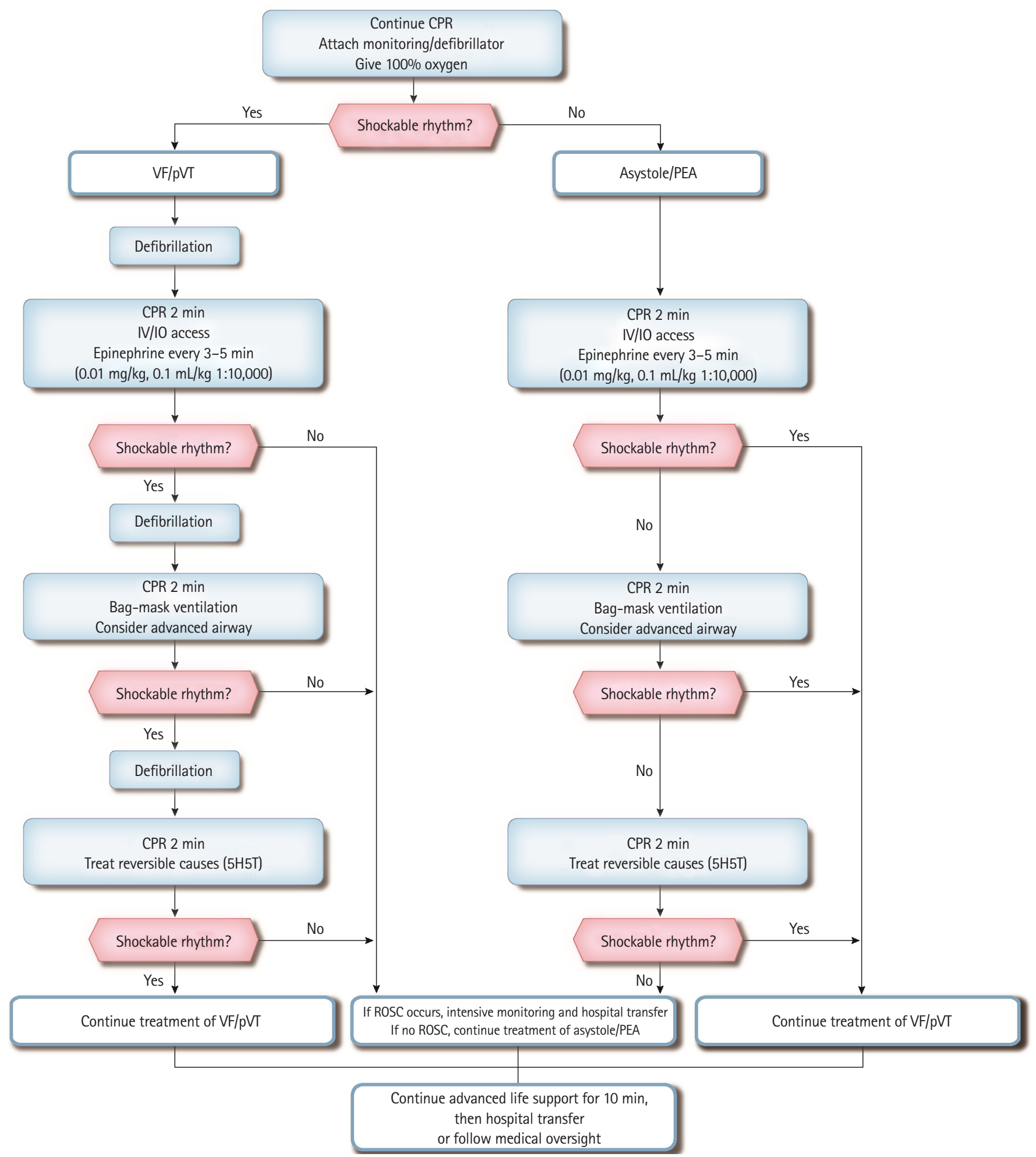

Fig. 2. Pediatric cardiac arrest algorithm for emergency medical team in the field. CPR, cardiopulmonary resuscitation; VF, ventricular fibrillation; pVT, pulseless ventricular tachycardia; PEA, pulseless electrical activity; IV, intravenous; IO, intraosseous; 5H, hypothermia, hypoxia, hypovolemia, hypokalemia/hyperkalemia, and hydrogen ion-acidosis; 5T, tamponade, thrombosis-pulmonary or cardiac, toxin, tension pneumothorax, and trauma; ROSC, return of spontaneous circulation. 


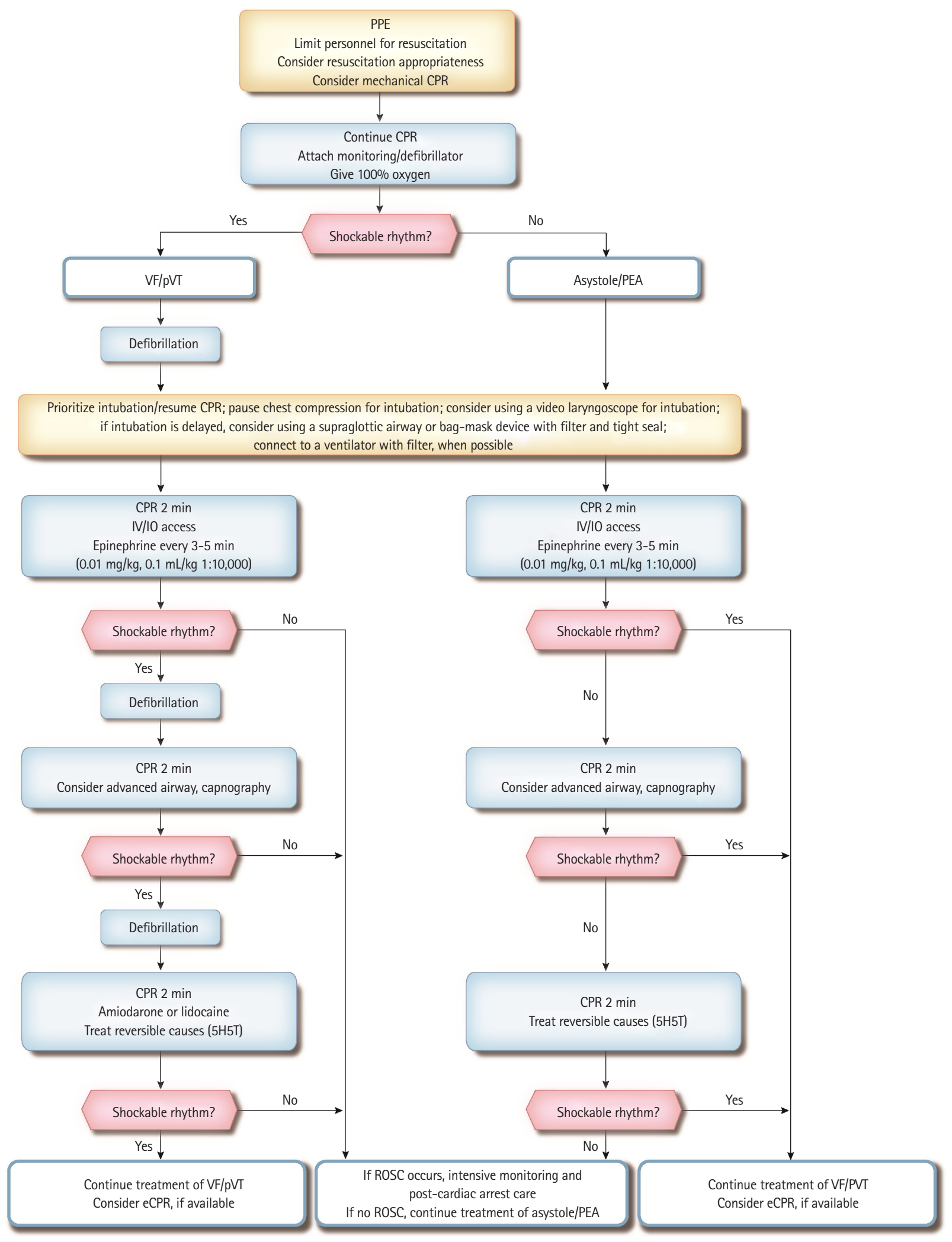

Fig. 3. Pediatric cardiac arrest algorithm for advanced life support team in the hospital in the COVID-19 pandemic state. PPE, personal protective equipment; CPR, cardiopulmonary resuscitation; VF, ventricular fibrillation; $p V T$, pulseless ventricular tachycardia; PEA, pulseless electrical activity; IV, intravenous; 10 , intraosseous; $5 \mathrm{H}$, hypothermia, hypoxia, hypovolemia, hypokalemia/hyperkalemia, and hydrogen ion-acidosis; $5 \mathrm{~T}$, tamponade, thrombosis-pulmonary or cardiac, toxin, tension pneumothorax, and trauma; eCPR, extracorporeal CPR; ROSC, return of spontaneous circulation. 


\section{Non-shockable rhythms (asystole/pulseless electrical activity)}

If the ECG rhythm is non-shockable, chest compression should be immediately performed. After a route for drug administration is achieved, administer $0.01 \mathrm{mg} / \mathrm{kg}$ epinephrine $(0.1 \mathrm{~mL} / \mathrm{kg}$ of 1:10,000 solution) every 3 to 5 minutes while continuing CPR. The rhythms must be checked again at the time of the chest compression shift, and if the rhythm is non-shockable, CPR should be continued with epinephrine administration until there is evidence of ROSC or a decision to stop resuscitation is made. If the rhythm changes to shockable, defibrillation must be performed any time and immediately chest compression must be restarted. And then, after 2 minutes, the rhythm should be checked again. To correct the reversible causes of pediatric cardiac arrest, $5 \mathrm{H}$ (hypothermia, hypoxia, hypovolemia, hypokalemia/hyperkalemia, and hydrogen ion-acidosis) and 5T (tamponade, thrombosis-pulmonary or cardiac, toxin, tension pneumothorax, and trauma) should be checked and corrected.

\section{Shockable rhythms (ventricular fibrillation/pulseless ventricular tachycardia)}

If shockable rhythms are confirmed, the first defibrillation is done at a dose of $2 \mathrm{~J} / \mathrm{kg}$. If the first defibrillation fails, there is no advantage in consecutively performing another with increased energy. Because CPR promotes perfusion of the coronary arteries and increases the likelihood of successful next defibrillation, it is more important to promptly initiate chest compressions than to perform additional defibrillation. Additionally, the rescuers should be thoroughly prepared for minimizing the interval between pausing the chest compressions and conducting defibrillation and restarting compression immediately after defibrillation. If an intravenous (IV) or intraosseous (IO) route for drug administration is achieved, administer epinephrine $(0.01 \mathrm{mg} / \mathrm{kg}$ or $0.1 \mathrm{~mL} / \mathrm{kg}$ of 1:10,000 solution) after the first shock and repeat administration every 3 to 5 minutes during CPR. After 2-minute CPR, rhythms should be rechecked. If organized rhythms are observed, pulse should be monitored to determine whether it is a perfusing rhythm. However, if shockable rhythms are maintained, defibrillation should be done at a dose of $4 \mathrm{~J} / \mathrm{kg}$ and compression must be immediately restarted. During the next cycle of CPR, preparations should be made by increasing the energy dose of the defibrillator charging (maximum $10 \mathrm{~J} / \mathrm{kg}$ or less than the dose for adults). In cases where defibrillation fails, amiodarone or lidocaine should be administered while continuing CPR. Whenever the rhythms become nonshockable, the cardiac arrest flowchart for non-shockable rhythms should be followed.

Torsades de pointes is polymorphic ventricular tachycardia (VT) associated with a prolonged QT interval. It typically rapidly proceeds to ventricular fibrillation (VF) or pulseless VT. Therefore, if pulseless VT- or VF-induced cardiac arrest occurs, a rescuer should initiate CPR and perform defibrillation. Magnesium (25-50 mg/kg, maximum single dose $2 \mathrm{~g}$ ) should be intravenously and rapidly (throughout several minutes) administered, regardless of the causes. Rescuers must also try to identify and manage other reversible causes, such as $5 \mathrm{Hs}$ and $5 \mathrm{Ts}$.

\section{ADVANCED AIRWAY MANAGEMENT}

There is no major change in the management of the airway from the 2015 guidelines for one-/two-rescuer bag-mask ventilation and endotracheal intubation. ${ }^{2}$

\section{SGA}

SGA is a type of airway device that assists ventilation when inserted into the pharynx, and one of the most common products is the laryngeal mask airway (LMA). The LMA is a tube with a cuffed mask at the end, which covers the upper side of the larynx to allow ventilation. For appropriate placement of LMA, it should be inserted until resistance is felt from the hypopharynx, following expansion of the cuff. If bag-mask ventilation or endotracheal intubation is not feasible, SGA can be used by an experienced operator. ${ }^{4-12}$ However, since this device is considerably more sensitive to the patient's movement than the endotracheal tube, attention should be paid while fixating it for preventing its displacement when moving the patients. The cause of cardiac arrest in children may be associated with respiratory issues; therefore, it is essential to check for the presence of any foreign body in the mouth or airway prior to SGA insertion.

\section{DRUG ADMINISTRATION DURING PALS}

\section{Routes of drug administration \\ 10 route}

10 route is a fast, safe, and effective technique for drug administration, fluid resuscitation, and laboratory testing in children and is particularly useful as the first route in case of cardiac arrest. $^{13-15}$ If IV access is unavailable in infants or children with severe shock or impending cardiac arrest, an 10 route should be primarily tried. ${ }^{15,16}$ Most of the resuscitation drugs, including epinephrine, atropine, and other catecholamines can be intraosseously administered, and there are no differences in the time to onset or the time to maximum hemodynamic response after 10 or IV injection. ${ }^{17}$ To help the drugs quickly reach the central circulation, it is recommended to inject 5 to $10 \mathrm{~mL}$ of normal saline fol- 
lowing each drug administration. A pressure bag or infusion pump can be used to facilitate the administration of high-viscosity drugs or to deliver fluids quickly. Blood tests such as electroIytes, blood types, and gas analysis are also possible immediately after securing an 10 route or within 15 minutes after CPR, and the results are similar to those obtained from venous blood. ${ }^{18}$

\section{IV route}

If a peripheral IV route can be quickly secured during CPR, it would be useful. However, it is very challenging to access the peripheral IV route of pediatric patients in an emergency situation. ${ }^{18}$ The central venous catheter (CVC) can be used safely for a long duration; however, it takes a significant amount of time to insert a CVC successfully and requires an experienced operator. Because of such limitations, CVC is not recommended as the initial route of drug administration in an emergency. Nevertheless, as a reliable route to reach blood circulation, CVC is significant in that it allows safe administration of drugs that can cause tissue damage when leaking into the surrounding area, such as vasoconstrictors, sodium bicarbonate, or calcium. To perform rapid fluid resuscitation with lesser resistance, a CVC with shorter length, wider diameter, and as few lumens as possible should be used.

\section{Endotracheal drug administration}

If IO or IV route is not feasible during resuscitation, the endotracheal administration limited to fat-soluble drugs (lidocaine, epinephrine, atropine, and naloxone) is possible, but the effect is not consistent. ${ }^{19}$ After drug administration, chest compressions should be discontinued and at least $5 \mathrm{~mL}$ saline solution should be administered. Thereafter, positive pressure ventilation should be performed five times. ${ }^{20}$ The appropriate dose of drugs for endotracheal administration is unknown; however, approximately 2 to 3 times the IV dose (10 times the IV dose for epinephrine) is typically recommended. Fat-insoluble drugs, such as sodium bicarbonate or calcium, should not be endotracheally administered because they cause tracheal injuries. ${ }^{21}$

\section{Measurement of patient weight in emergency situations} In emergency situations, the drug dosage for the pediatric patients should be determined by weight. Experienced medical staff may not accurately estimate the patient's weight based on the physical appearance. A method using a weight estimation formula according to the age is not feasible because the age of a patient may also be unknown, and the range of normal weights by age is too broad. ${ }^{22}$ However, the height can be easily measured in emergency, and the patient's weight can be estimated relatively accurately using the height. ${ }^{23}$ After estimating the weight from height, the resuscitation tape that contains the calculated doses of drugs by estimated weight should be used. ${ }^{22,24,25}$ It is recommended to use the Korean Pediatric Emergency Tape produced by the Korean Association of Cardiopulmonary Resuscitation in 2018. However, if a child weight $>25 \mathrm{~kg}$ or is relatively old, the weight estimated from the height may be less than the actual weight. ${ }^{24,26,27}$

\section{Drugs used for PALS (Table 1) Epinephrine}

Vasoconstriction mediated by the a-adrenergic receptor is the most important pharmacological action of epinephrine in cardiac arrest. Vasoconstriction increases aortic diastolic pressure, leading to an increase in coronary perfusion pressure, which is an important determinant for successful CPR. ${ }^{28,29}$ Coronary perfusion pressure, increased by epinephrine during chest compressions, increases oxygen supply to the heart. Furthermore, epinephrine increases cardiac contractility and stimulates spontaneous contractions, improving the success rate of defibrillation by increasing the amplitude of VF.

In children with bradycardia accompanied by symptoms and who are nonresponsive to effective ventilation or oxygenation, epinephrine can be administered. The most common rhythms observed in pediatric patients with cardiac arrest are asystole and bradycardia. Epinephrine may generate a rhythm that enables perfusion in such patients. Particularly, the rapid administration within 5 minutes after cardiac arrest has a good effect on prognosis of a patient. ${ }^{30}$ The dose of epinephrine for initial resuscitation is $0.01 \mathrm{mg} / \mathrm{kg}(0.1 \mathrm{~mL} / \mathrm{kg}$ of 1:10,000 solution), when it is intravenously or intraosseously administered. Epinephrine is repeatedly administered with the same dose every 3 to 5 minutes during resuscitation. The degree of drug absorption and blood concentration is unpredictable, but the endotracheal administration of epinephrine is also considered if the IV or 10 route is not feasible (recommended dose: $0.1 \mathrm{mg} / \mathrm{kg}$ or $0.1 \mathrm{~mL} / \mathrm{kg}$ of 1:1,000 solution). Because acidosis or hypoxia may cause a decline in catecholamine activities, it is important to focus on ventilation, oxygenation, and circulation. Epinephrine is inactivated by alkaline solutions; therefore, it should not be mixed with sodium bicarbonate.

\section{Amiodarone}

Amiodarone delays atrioventricular (AV) nodal conduction, prolongs the refractory period, increases $\mathrm{OT}$ intervals, and delays ventricular conduction. The drug can be administered to the following patients: supraventricular tachycardia not responding to adenosine administration and cardiac arrest with VF/pulseless VT. In cardiac arrest, amiodarone at a dose of $5 \mathrm{mg} / \mathrm{kg}$ can be intravenously or intraosseously administered. If a pulse is present, it can 
Table 1. Medications commonly used in pediatric advanced life support

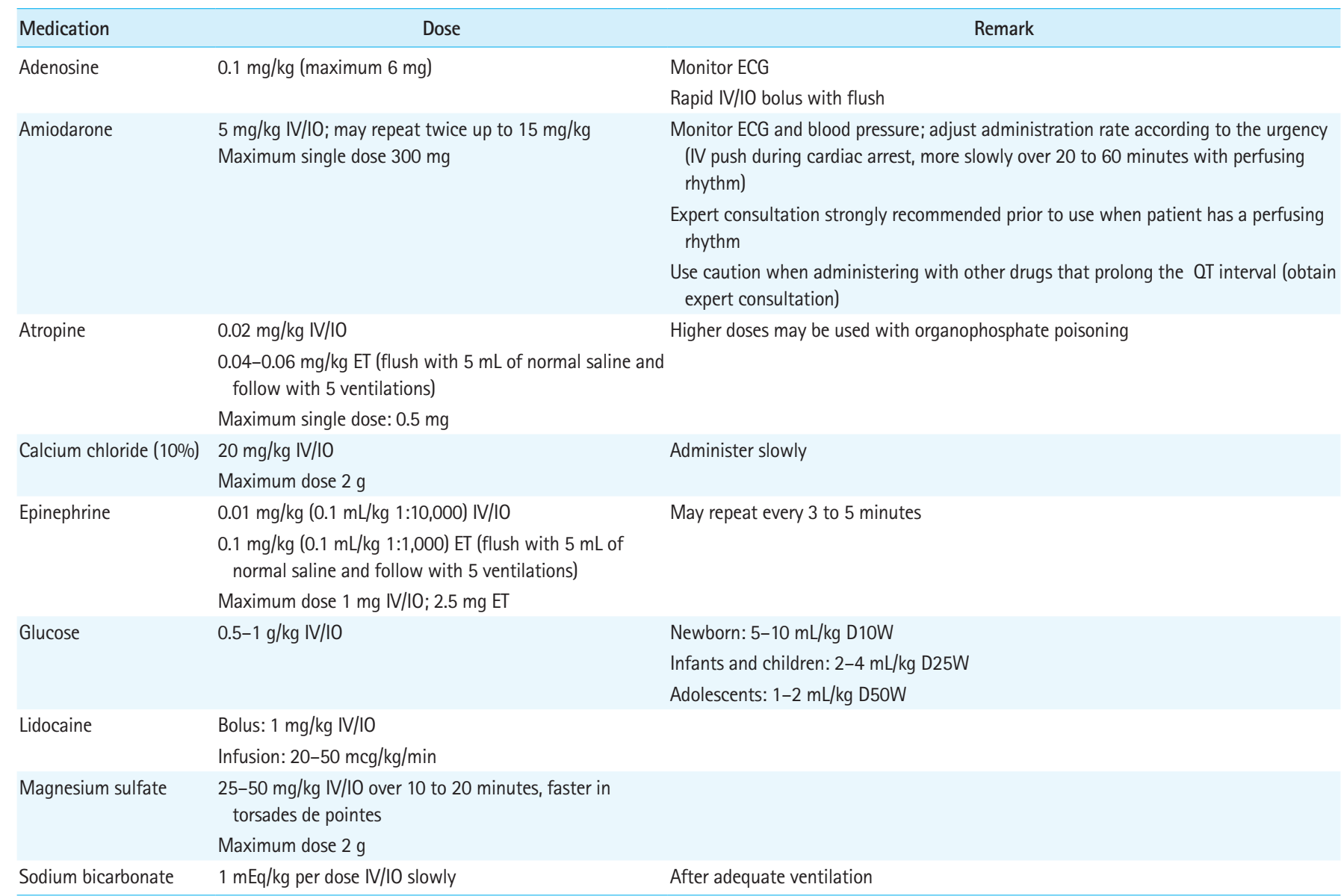

ECG, electrocardiogram; IV, intravenous; IO, intraosseous; ET, endotracheal.

be slowly administered; however, in cardiac arrest, it should be administered quickly. During the administration of amiodarone, hypotension may occur due to the vasodilating action. When this drug is administered, the occurrence of complications, such as bradycardia, AV block, and torsades de pointes, should be monitored via ECG. Caution is all the more necessary when amiodarone is co-administered with drugs that induce QT prolongation.

\section{Lidocaine}

Lidocaine lowers myocardial automaticity and inhibits ventricular arrhythmias. In infants and children with VF/pulseless VT that does not respond to defibrillation, either amiodarone or lidocaine can be used. ${ }^{31-33}$ When VF/pulseless VT nonresponsive to defibrillation persists after the rapid administration of $1 \mathrm{mg} / \mathrm{kg}$ of the drug, the administration can be repeated every 5 to 10 minutes.

\section{Adenosine}

Adenosine temporarily blocks AV nodal conduction and interrupts the re-entry mechanism. The half-life of adenosine is extremely short at $<10$ seconds; therefore, adenosine has a wide safety range. When administered via the peripheral route, a higher dose may be required than via the central line. Intraosseous adenosine administration is feasible, and the dose is the same as that of the IV administration. Additional normal saline should be provided immediately after rapid IV adenosine administration within 1 to 2 seconds to deliver adenosine into the central circulation.

\section{Atropine}

Atropine is a parasympatholytic agent that increases heart rate and improves AV conduction. There is no evidence to administer atropine in CPR. Atropine can be used only when there is a high risk of bradycardia in emergency endotracheal intubation, such as hypovolemic state or usage of succinylcholine. ${ }^{34}$ However, the routine administration of atropine during endotracheal intubation is not recommended in infants and children. ${ }^{31,35,36} \mathrm{~A}$ dose of $0.02 \mathrm{mg} / \mathrm{kg}$ is intravenously/intraosseously administered and used without a minimum dose. 
Glucose

Infants and children have high glucose requirements and little glycogen is stored. Accordingly, they can easily become hypoglycemic when the energy requirements increase. Therefore, in cases of coma, shock, or respiratory failure, the blood glucose level should be carefully monitored at the bedside. If low level of blood glucose is confirmed, it should be treated with a fluid containing glucose. ${ }^{37}$ Because high glucose solution may result in thrombosis, hyperglycemia, and intracranial hemorrhage in infants, 10\% or 25\% (1:1 diluted 50\% glucose) glucose solution should be administered. It is recommended to treat hypoglycemia with an IV bolus injection of 0.5 to $1.0 \mathrm{~g} / \mathrm{kg}$ of glucose, followed by constant glucose fluid administration.

Sodium bicarbonate, calcium, magnesium

There is no change from the 2015 PALS guideline. ${ }^{2}$

\section{DEFIBRILLATION}

The ideal defibrillator would be the one containing a device that controls the energy dose for children. When using a manual defibrillator, the following instructions should be considered.

\section{Size of electrodes}

Typically, manual defibrillators are equipped with two sizes of electrodes, one for adults and the other for infants. Infant electrodes are superimposed above or below the adult electrodes. During defibrillation, the largest electrodes suitable for the chest of children should be used. The distance between the electrodes should be at least $3 \mathrm{~cm}$ so that they do not touch each other. The defibrillation effect remains the same regardless of the type of electrodes. Electrodes of adult sizes $(8-10 \mathrm{~cm})$ are used for children weighing over $10 \mathrm{~kg}$ or aged $>1$ year and those of infant sizes are used for infants weighing $<10 \mathrm{~kg}$ or aged $<1$ year.

\section{Contact surfaces and electrode placement}

Electrode gel must be applied when manual electrodes are used. Saline, ultrasound gel, and alcohol should not be used as a substitute for electrode gel. Manual electrodes are placed on the right side of the chest and the apical region (on the left side of a nipple over the lower ribs in the left side) to ensure that the heart can be located between two electrodes. Pressure should be firmly applied to the electrodes against the chest. There are no particular merits of positioning electrodes anterior and posterior to the rib cage; however, if the two electrodes are too close to each other (within $3 \mathrm{~cm}$ ), they can be placed at those positions.

\section{Dose of energy}

When infants and children have VF or pulseless VT, the first energy dose of $2 \mathrm{~J} / \mathrm{kg}$ in both monophasic or biphasic defibrillators is recommended. Energy dose from the second defibrillation should be greater than or equal to $4 \mathrm{~J} / \mathrm{kg}$ and should not exceed the maximum dose in adults. If there is no applicable energy dose in a defibrillator, the next highest energy dose on the panel should be used. $^{38-40}$

\section{Extracorporeal CPR}

Extracorporeal CPR (ECPR) refers to CPR with the application of venoarterial ECMO in patients with no ROSC. CPR using ECMO requires various resources and multidisciplinary collaboration; therefore, its usage is limited to hospitals with adequate facilities. A study has reported that ECPR improves the prognosis after cardiac arrest; however, to date, evidence for a conclusive statement about its use in all cardiac arrests remains insufficient. ${ }^{41-52}$ In children who underwent CPR for $>10$ minutes due to IHCA, improved survival discharge rates and good neurological outcomes were reported when ECPR was performed. ${ }^{45}$ Therefore, in case of pediatric IHCA, ECPR can be considered when the hospital has a protocol for CPR using ECMO, trained experts, and specialized equipment. ${ }^{53}$ However, there is still not enough evidence to use ECMO as the basic treatment for CPR in non-cardiac causes of arrest. ${ }^{54-56}$

\section{PATIENT MONITORING DURING CPR}

In CPR for infants and children, patient monitoring can help improve outcomes as it can support high-quality CPR such as effective chest compression, adequate respiration support, and evaluation of ROSC.

\section{ECG}

The ECG electrodes should be attached as soon as possible to check the rhythm and manage it appropriately. Constant ECG monitoring is recommended to evaluate the response to drugs during resuscitation.

\section{Pulse oximetry}

Measurement of oxygen saturation using pulse oximetry is not a proper monitoring method during CPR because pulsatile blood flow to the peripheral tissues is poor when the cardiac output decreases.

\section{Echocardiography}

Echocardiography is helpful in identifying correctable causes of cardiac arrest (cardiac tamponade, complex cardiac malforma- 
tions related disorders, pulmonary embolism, etc.), which may occur related to cardiac disorders. However, owing to the small body size of children, chest compression inevitably needs to be discontinued to ensure adequate visibility for echocardiography, and the ability to find correctable causes is also limited. Therefore, given the risk and benefit of performing an echocardiography, there is insufficient evidence for its usefulness in pediatric CPR.

\section{Blood pressure}

If a patient in a pediatric intensive care unit (ICU) has an arterial line, the adequacy of chest compressions and ROSC can be evaluated and identified through pressure waveform and blood pressure monitoring during CPR. Controlling chest compression and relaxation, along with monitoring the arterial systolic and diastolic blood pressure, can help maintain adequate coronary blood flow and cerebral blood flow and ultimately improve CPR outcomes and prognosis. However, there is no sufficient and accurate evidence of an association between inserting invasive hemodynamic monitoring devices during CPR for monitoring and the patient prognosis.

\section{$\mathrm{EtCO}_{2}$ monitoring}

In cardiac arrest, end-tidal $\mathrm{CO}_{2}\left(\mathrm{EtCO}_{2}\right)$ is almost zero because there is no blood flow that delivers $\mathrm{CO}_{2}$ constantly produced by the body to the lungs. When CPR is performed, gas is delivered to the lungs by an increased blood flow in the pulmonary arteries. Accordingly, $\mathrm{EtCO}_{2}$ is proportional to the cardiac output if ventilation is constant. Therefore, continuous monitoring of $\mathrm{EtCO}_{2}$ is helpful in evaluating the adequacy of chest compressions during $\mathrm{CPR}$. If $\mathrm{EtCO}_{2}$ is consistently $<10 \mathrm{mmHg}$ during resuscitation, efforts must be made to increase cardiac output by performing chest compressions more effectively; meanwhile, it may result from hyperventilation. $\mathrm{EtCO}_{2}>30 \mathrm{mmHg}$ can be considered as an indicator of ROSC. Measurement of $\mathrm{EtCO}_{2}$ can be a method of identifying ROSC more quickly than palpating a pulse between chest compressions..$^{57}$ However, it is necessary to recognize the effect of drug administration. ${ }^{58,59}$ When a vasoconstrictor such as epinephrine is administered, pulmonary blood flow decreases, leading to a reduction in $\mathrm{EtCO}_{2}$. After sodium bicarbonate administration, $\mathrm{EtCO}_{2}$ can increase.

In a recent prospective multi-center pediatric ICU study, $\mathrm{EtCO}_{2}$ of $>20 \mathrm{mmHg}$ during CPR was not related to survival to discharge rates or ROSC rates, and there was no difference in $\mathrm{EtCO}_{2}$ between survivors and non-survivors. ${ }^{60}$ However, the researchers suggested that further studies are required to evaluate the usefulness of capnography in pediatric CPR because the present study might be affected by the ventilation status of patients and drug administration.

\section{CARDIAC ARREST DUE TO MYOCARDITIS AND DILATED CARDIOMYOPATHY}

In case of patients with acute myocarditis who have ECG abnormalities such as AV block and ST segment changes, close monitoring in pediatric ICU is recommended owing to the high probability of cardiac arrest. ${ }^{61}$ Early implementation of extracorporeal circulatory assistance in patients with decreased cardiac output due to myocarditis or dilated cardiomyopathy may help prevent arrest, but the evidence is still insufficient. ${ }^{62-64}$ Since successful ROSC in these children is very difficult, it is recommended to early transfer them to hospitals where extracorporeal circulatory assistance such as ECMO or ventricular assistance devices are available.

\section{POST-CPR MANAGEMENT}

It is recommended to treat patients with cardiac arrest who have achieved RSOC in an ICU where intensive care is available. To maintain adequate ventilation and oxygenation, the respiratory and the cardiovascular system should be managed, and active management of respiratory failure and shock is required. If the patient is in a coma state, TTM can be considered. For further basic management based on organs, refer to the 2015 guideline. $^{2}$

\section{TTM}

In a recent systematic review that included two randomized clinical trials and eight cohort studies, 2,060 pediatric patients in coma with ROSC were analyzed. ${ }^{65} \mathrm{Compared}$ with $\Pi \mathrm{TM}$ at $32^{\circ} \mathrm{C}$ to $34^{\circ} \mathrm{C}$ there was no difference in neurological outcomes, survival rates, and adverse effects when $T \mathrm{M}$ was at $36^{\circ} \mathrm{C}$ to $37.5^{\circ} \mathrm{C}$ or no active temperature management was performed. ${ }^{65}$ Meanwhile, a subanalysis showed that in pediatric patients with OHCA, TM at $32^{\circ} \mathrm{C}$ to $34^{\circ} \mathrm{C}$ improved the short-term (30 days) and mid-term (6 months) survival rates compared with $\Pi \mathrm{MM}$ at $36-37.5^{\circ} \mathrm{C}$ or no TTM. ${ }^{66}$ However, in children with IHCA, $\Pi \mathrm{MM}$ at $32^{\circ} \mathrm{C}$ to $34^{\circ} \mathrm{C}$ showed statistical harm to the neurological outcomes and survival rates at 3 to 6 months. ${ }^{67}$ On sub-analysis of pediatric patients with asphyxial cardiac arrest, $\Pi \mathrm{M}$ at $32^{\circ} \mathrm{C}$ to $34^{\circ} \mathrm{C}$ was associated with improvement of the short-term (30 days) and mid-term (6 months) survival rates compared with $\Pi \mathrm{M}$ at $36^{\circ} \mathrm{C}$ to $37.5^{\circ} \mathrm{C}$ or no $\Pi \mathrm{M}$. However, in cardiac arrest caused by drowning and psychogenic reasons, there was no difference in survival rates and neurological prognosis. Consequently, there is inadequate evidence for recommending $\mathrm{TTM}$ at specific temperatures (approximately $32^{\circ} \mathrm{C}$ to 
$34^{\circ} \mathrm{C}$ or $36^{\circ} \mathrm{C}$ to $37.5^{\circ} \mathrm{C}$ ) after ROSC in pediatric patients. However, since several studies showed hyperthermia in considerable cases during post-CPR and reported that fever is associated with poor neurological prognosis, it is expected that TM will be able to treat and prevent an increase in body temperature. Therefore, in pediatric patients who achieved ROSC after cardiac arrest, body temperature should be actively monitored to prevent fever regardless of TM. Furthermore, it is recommended to set the target temperature between $32^{\circ} \mathrm{C}$ to $34^{\circ} \mathrm{C}$ or $36^{\circ} \mathrm{C}$ to $37.5^{\circ} \mathrm{C}$ when implementing $\mathrm{TM}$.

\section{Respiratory system}

In all infants and children who recover from $\mathrm{CPR}_{1} \mathrm{PaO}_{2}$ and $\mathrm{PCO}_{2}$ should be measured, and adequate goals should be set up to manage it. There is no randomized controlled trial comparing survival rates and neurological prognosis according to target values of $\mathrm{PaO}_{2}$ and $\mathrm{PCO}_{2}$ in children following resuscitation. However, in observational studies with the low level of evidence, hyperoxemia or hypoxemia was not related to prognosis and both hypercapnia and hypocapnia were reportedly related to low survival rates. ${ }^{68-71}$ Therefore, it is recommended to maintain normal $\mathrm{PaO}_{2}$ and $\mathrm{PCO}_{2}$ in children after ROSC, if there is no other specific goal. However, in patients with congenital heart disease, appropriate $\mathrm{PaO}_{2}$ can differ from that in patients with a normal cardiovascular system according to the anatomical and physiological conditions. Therefore, in pediatric patients, cardiovascular malformation should be evaluated immediately after resuscitation; if suspected, early evaluation including echocardiography should be considered.

\section{Cardiovascular system}

Since circulatory disorders often persist after recovery from cardiac arrest, the cardiovascular system should be constantly evaluated for the early detection of decreased cardiac output and occurrence of shock. Heart rate, blood pressure, and oxygen saturation is continuously monitored, and direct evaluation of patients should be also repeated at least every 5 minutes. In hemodynamically unstable children, blood pressure measured with cuff may be inaccurate, thus blood pressure monitoring via arterial line is recommended in patients with cardiovascular dysfunction. During post-CPR management, systolic blood pressure should be maintained at least in the 5th percentile by age through IV fluid resuscitation or drug administration. ${ }^{72-74} \mathrm{~A}$ fluid bolus of $20 \mathrm{~mL} / \mathrm{kg}$ should first be given, unless cardiac function is decreased. If hypotensive shock persists, epinephrine, dopamine, and norepinephrine administration can be considered. On the other hand, when normotensive shock appears, dobutamine, dopamine, epinephrine, or milrinone administration can be considered. The selection and dose of all drugs should be personalized to an individual patient and be administered via a secure IV route. Meanwhile, the correctible causes of shock, such as 5Hs and 5Ts, should be checked.

To identify the circulatory status of patients, central venous blood, arterial blood gas analysis, serum electrolyte, glucose, calcium, and lactate levels should be measured. It is necessary to consult with specialized departments, and if the facility is a small medical institute with limited resources, the patient should be transferred to a tertiary hospital.

\section{Nervous system}

The primary goal of CPR is maintaining brain function. Even after resuscitation, care must be taken to prevent secondary nervous system injury. Neurophysiological monitoring such as EEG can help to identify the patient's neurological status and establish the prognosis. Non-convulsive seizures and non-convulsive status epilepticus are common after pediatric cardiac arrest, and it is difficult to identify them without EEG monitoring. ${ }^{75-78}$ Convulsive and non-convulsive status epilepticus are associated with poor prognosis. ${ }^{77}$ Therefore, it is recommended to constantly monitor the EEG for identifying any kind of seizures in children, if possible. Moreover, if there is clinical seizure, it must be treated, and in case of non-convulsive status epilepticus, consulting neurologists is recommended. ${ }^{79,80} \mathrm{EEG}$ monitoring within 1 week of cardiac arrest helps predict the prognosis of cardiac arrest. ${ }^{78,80-83}$ In addition, it can help identify seizures in patients using ECMO. However, further studies are required to identify whether such monitoring can improve the neurological prognosis.

\section{PREDICTORS OF OUTCOMES}

There are no established predictors of neurological and survival outcomes in children with ROSC. It is recommended to select clinical, hematological, and imaging tests suggested in the guidelines according to the hospital environment. In children with ROSC from OHCA and IHCA, blood pressure monitoring and DNI can be considered to predict survival to discharge rates and short-term survival rates. ${ }^{84,85}$ Furthermore, EEG monitoring to detect seizures and biochemical marker tests including blood NSE, S100 proteins, $\mathrm{DNI}$, and diffusion-weighted magnetic resonance imaging can be considered to predict the neurological prognosis. ${ }^{84,86-89} \mathrm{~A}$ singlecenter retrospective observational study that targeted pediatric patients with OHCA showed that lactate level, Glasgow coma scale score, and the response to the pupillary light reflex test (which was conducted before initiating TM immediately after ROSC) were factors that were significantly associated with the 6-month neurological prognosis. ${ }^{90}$ 


\section{CONFLICT OF INTEREST}

No potential conflict of interest relevant to this article was reported.

\section{ACKNOWLEDGMENTS}

This study was supported by a grant (2020E330300) of the Korean Disease Control and Prevention Agency funded by the Ministry of Health and Welfare, Republic of Korea.

We thank Ms. So Yeong Kim (EMT) for her assistance with administrative affairs and Mr. Myung Ha Kim for his assistance with literature searches for updating the Korean Guidelines for Cardiopulmonary Resuscitation. We also thank the Korean Association of Cardiopulmonary Resuscitation (KACPR) for supporting the process of proofreading.

\section{REFERENCES}

1. Maconochie IK, Aickin $R$, Hazinski MF, et al. Pediatric Life Support 2020 international consensus on cardiopulmonary resuscitation and emergency cardiovascular care science with treatment recommendations. Pediatrics 2021;147(Suppl 1):e2020 038505B.

2. Kim DK, Jhang WK, Ahn JY, et al. Part 6. Pediatric advanced life support: 2015 Korean guidelines for cardiopulmonary resuscitation. Clin Exp Emerg Med 2016;3(Suppl):S48-61.

3. Nolan JP, Monsieurs KG, Bossaert L, et al. European Resuscitation Council COVID-19 guidelines executive summary. Resuscitation 2020;153:45-55.

4. Carenzi $B$, Corso RM, Stellino V, et al. Airway management in an infant with congenital centrofacial dysgenesia. Br J Anaesth 2002;88:726-8.

5. Fraser J, Hill C, McDonald D, Jones C, Petros A. The use of the laryngeal mask airway for inter-hospital transport of infants with type 3 laryngotracheo-oesophageal clefts. Intensive Care Med 1999;25:714-6.

6. Iohom G, Lyons B, Casey W. Airway management in a baby with femoral hypoplasia-unusual facies syndrome. Paediatr Anaesth 2002;12:461-4.

7. Johr M, Berger TM, Ruppen W, Schlegel C. Congenital laryngotracheo-oesophageal cleft: successful ventilation with the Laryngeal Mask Airway. Paediatr Anaesth 2003;13:68-71.

8. Leal-Pavey YR. Use of the LMA classic to secure the airway of a premature neonate with Smith-Lemli-Opitz syndrome: a case report. AANA J 2004;72:427-30.

9. Russell P, Chambers N, du Plessis J, Vijayasekeran S. Emergen- cy use of a size 1 laryngeal mask airway in a ventilated neonate with an undiagnosed type IV laryngotracheo-oesophageal cleft. Paediatr Anaesth 2008;18:658-62.

10. Scheller B, Schalk R, Byhahn C, et al. Laryngeal tube suction II for difficult airway management in neonates and small infants. Resuscitation 2009;80:805-10.

11. Stocks RM, Egerman R, Thompson JW, Peery M. Airway management of the severely retrognathic child: use of the laryngeal mask airway. Ear Nose Throat J 2002;81:223-6.

12. Yao CT, Wang JN, Tai YT, Tsai TY, Wu JM. Successful management of a neonate with Pierre-Robin syndrome and severe upper airway obstruction by long term placement of a laryngeal mask airway. Resuscitation 2004;61:97-9.

13. Brunette DD, Fischer R. Intravascular access in pediatric cardiac arrest. Am J Emerg Med 1988;6:577-9.

14. Horton MA, Beamer C. Powered intraosseous insertion provides safe and effective vascular access for pediatric emergency patients. Pediatr Emerg Care 2008;24:347-50.

15. Banerjee S, Singhi SC, Singh S, Singh M. The intraosseous route is a suitable alternative to intravenous route for fluid resuscitation in severely dehydrated children. Indian Pediatr 1994;31:1511-20.

16. Kanter RK, Zimmerman JJ, Strauss RH, Stoeckel KA. Pediatric emergency intravenous access. Evaluation of a protocol. Am J Dis Child 1986;140:132-4.

17. Andropoulos DB, Soifer SJ, Schreiber MD. Plasma epinephrine concentrations after intraosseous and central venous injection during cardiopulmonary resuscitation in the lamb. J Pediatr 1990;116:312-5.

18. Johnson L, Kissoon N, Fiallos M, Abdelmoneim T, Murphy S. Use of intraosseous blood to assess blood chemistries and hemoglobin during cardiopulmonary resuscitation with drug infusions. Crit Care Med 1999:27:1147-52.

19. Johnston C. Endotracheal drug delivery. Pediatr Emerg Care 1992:8:94-7.

20. Jasani MS, Nadkarni VM, Finkelstein MS, Mandell GA, Salzman SK, Norman ME. Effects of different techniques of endotracheal epinephrine administration in pediatric porcine hypoxic-hypercarbic cardiopulmonary arrest. Crit Care Med 1994; 22:1174-80.

21. Raehl CL. Endotracheal drug therapy in cardiopulmonary resuscitation. Clin Pharm 1986;5:572-9.

22. Lubitz DS, Seidel JS, Chameides L, Luten RC, Zaritsky AL, Campbell FW. A rapid method for estimating weight and resuscitation drug dosages from length in the pediatric age group. Ann Emerg Med 1988;17:576-81.

23. Garland JS, Kishaba RG, Nelson DB, Losek JD, Sobocinski KA. 
A rapid and accurate method of estimating body weight. Am J Emerg Med 1986;4:390-3.

24. Young KD, Korotzer NC. Weight Estimation methods in children: a systematic review. Ann Emerg Med 2016;68:441-51.

25. Jang HY, Shin SD, Kwak YH. Can the Broselow tape be used to estimate weight and endotracheal tube size in Korean children? Acad Emerg Med 2007;14:489-91.

26. So TY, Farrington $E$, Absher RK. Evaluation of the accuracy of different methods used to estimate weights in the pediatric population. Pediatrics 2009;123:e1045-51.

27. Hofer CK, Ganter M, Tucci M, Klaghofer R, Zollinger A. How reliable is length-based determination of body weight and tracheal tube size in the paediatric age group? The Broselow tape reconsidered. Br J Anaesth 2002;88:283-5.

28. Niemann JT, Criley JM, Rosborough JP, Niskanen RA, Alferness C. Predictive indices of successful cardiac resuscitation after prolonged arrest and experimental cardiopulmonary resuscitation. Ann Emerg Med 1985;14:521-8.

29. Sanders AB, Ewy GA, Taft TV. Prognostic and therapeutic importance of the aortic diastolic pressure in resuscitation from cardiac arrest. Crit Care Med 1984;12:871-3.

30. Andersen LW, Berg KM, Saindon BZ, et al. Time to epinephrine and survival after pediatric in-hospital cardiac arrest. JAMA 2015;314:802-10.

31. Jones $P$, Dauger $S$, Denjoy I, et al. The effect of atropine on rhythm and conduction disturbances during 322 critical care intubations. Pediatr Crit Care Med 2013;14:e289-97.

32. Valdes SO, Donoghue AJ, Hoyme DB, et al. Outcomes associated with amiodarone and lidocaine in the treatment of inhospital pediatric cardiac arrest with pulseless ventricular tachycardia or ventricular fibrillation. Resuscitation 2014;85:381-6.

33. Dorian P, Cass D, Schwartz B, Cooper R, Gelaznikas R, Barr A. Amiodarone as compared with lidocaine for shock-resistant ventricular fibrillation. N Engl J Med 2002;346:884-90.

34. Quintard H, l'Her $E_{1}$ Pottecher J, et al. Experts' guidelines of intubation and extubation of the ICU patient of French Society of Anaesthesia and Intensive Care Medicine (SFAR) and French-speaking Intensive Care Society (SRLF): in collaboration with the pediatric Association of French-speaking Anaesthetists and Intensivists (ADARPEF), French-speaking Group of Intensive Care and Paediatric emergencies (GFRUP) and Intensive Care physiotherapy society (SKR). Ann Intensive Care 2019;9:13.

35. Fastle RK, Roback MG. Pediatric rapid sequence intubation: incidence of reflex bradycardia and effects of pretreatment with atropine. Pediatr Emerg Care 2004;20:651-5.

36. Jones P, Peters MJ, Pinto da Costa N, et al. Atropine for criti- cal care intubation in a cohort of 264 children and reduced mortality unrelated to effects on bradycardia. PLoS One 2013; 8:e57478.

37. Beiser DG, Carr GE, Edelson DP, Peberdy MA, Hoek TL. Derangements in blood glucose following initial resuscitation from inhospital cardiac arrest: a report from the national registry of cardiopulmonary resuscitation. Resuscitation 2009;80:62430.

38. Rodriguez-Nunez A, Lopez-Herce J, del Castillo J, Bellon JM; Iberian-American Paediatric Cardiac Arrest Study Network RIBEPCI. Shockable rhythms and defibrillation during in-hospital pediatric cardiac arrest. Resuscitation 2014;85:387-91.

39. Gutgesell HP, Tacker WA, Geddes LA, Davis S, Lie JT, McNamara DG. Energy dose for ventricular defibrillation of children. Pediatrics 1976;58:898-901.

40. Meaney PA, Nadkarni VM, Atkins DL, et al. Effect of defibrillation energy dose during in-hospital pediatric cardiac arrest. Pediatrics 2011;127:e16-23.

41. Torres-Andres F, Fink EL, Bell MJ, Sharma MS, Yablonsky EJ, Sanchez-de-Toledo J. Survival and long-term functional outcomes for children with cardiac arrest treated with extracorporeal cardiopulmonary resuscitation. Pediatr Crit Care Med 2018;19:451-8.

42. Pozzi M, Armoiry $X$, Achana F, et al. Extracorporeal life support for refractory cardiac arrest: a 10-year comparative analysis. Ann Thorac Surg 2019;107:809-16.

43. Park JH, Song KJ, Shin SD, Ro YS, Hong KJ. Time from arrest to extracorporeal cardiopulmonary resuscitation and survival after out-of-hospital cardiac arrest. Emerg Med Australas 2019;31:1073-81.

44. Meert KL, Guerguerian AM, Barbaro R, et al. Extracorporeal cardiopulmonary resuscitation: one-year survival and neurobehavioral outcome among infants and children with inhospital cardiac arrest. Crit Care Med 2019;47:393-402.

45. Lasa JJ, Rogers RS, Localio R, et al. Extracorporeal Cardiopulmonary Resuscitation (E-CPR) during pediatric in-hospital cardiopulmonary arrest is associated with improved survival to discharge: a report from the American Heart Association's Get With The Guidelines-Resuscitation (GWTG-R) Registry. Circulation 2016;133:165-76.

46. Kramer P, Mommsen A, Miera O, Photiadis J, Berger F, Schmitt KRL. Survival and mid-term neurologic outcome after extracorporeal cardiopulmonary resuscitation in children. Pediatr Crit Care Med 2020;21:e316-24.

47. Holmberg MJ, Geri G, Wiberg S, et al. Extracorporeal cardiopulmonary resuscitation for cardiac arrest: a systematic review. Resuscitation 2018;131:91-100. 
48. Shin HJ, Song S, Park HK, Park YH. Results of extracorporeal cardiopulmonary resuscitation in children. Korean J Thorac Cardiovasc Surg 2016;49:151-6.

49. Shakoor A, Pedroso FE, Jacobs SE, et al. Extracorporeal Cardiopulmonary Resuscitation (ECPR) in infants and children: a single-center retrospective study. World J Pediatr Congenit Heart Surg 2019;10:582-9.

50. Conrad SA, Rycus PT. Extracorporeal membrane oxygenation for refractory cardiac arrest. Ann Card Anaesth 2017;20(Supplement):S4-10.

51. Bembea MM, Ng DK, Rizkalla N, et al. Outcomes after extracorporeal cardiopulmonary resuscitation of pediatric in-hospital cardiac arrest: a report from the Get With the Guidelines-Resuscitation and the Extracorporeal Life Support Organization Registries. Crit Care Med 2019;47:e278-85.

52. Tan BK. Extracorporeal membrane oxygenation in cardiac arrest. Singapore Med J 2017;58:446-8.

53. Lowry AW, Morales DL, Graves DE, et al. Characterization of extracorporeal membrane oxygenation for pediatric cardiac arrest in the United States: analysis of the kids' inpatient database. Pediatr Cardiol 2013;34:1422-30.

54. Ortmann L, Prodhan P, Gossett J, et al. Outcomes after inhospital cardiac arrest in children with cardiac disease: a report from Get With the Guidelines-Resuscitation. Circulation 2011;124:2329-37.

55. Odegard KC, Bergersen $L$, Thiagarajan $R$, et al. The frequency of cardiac arrests in patients with congenital heart disease undergoing cardiac catheterization. Anesth Analg 2014;118: $175-82$.

56. de Mos N, van Litsenburg RR, McCrindle B, Bohn DJ, Parshuram CS. Pediatric in-intensive-care-unit cardiac arrest: incidence, survival, and predictive factors. Crit Care Med 2006;34:120915.

57. Pokorna M, Necas E, Kratochvil J, Skripsky R, Andrlik M, Franek 0 . A sudden increase in partial pressure end-tidal carbon dioxide $(\mathrm{P}(\mathrm{ET}) \mathrm{CO}(2))$ at the moment of return of spontaneous circulation. J Emerg Med 2010;38:614-21.

58. Kleinman ME, Chameides L, Schexnayder SM, et al. Pediatric advanced life support: 2010 American Heart Association guidelines for cardiopulmonary resuscitation and emergency cardiovascular care. Pediatrics 2010;126:e1361-99.

59. Cantineau JP, Merckx P, Lambert Y, Sorkine M, Bertrand C, Duvaldestin P. Effect of epinephrine on end-tidal carbon dioxide pressure during prehospital cardiopulmonary resuscitation. Am J Emerg Med 1994;12:267-70.

60. Berg RA, Reeder RW, Meert KL, et al. End-tidal carbon dioxide during pediatric in-hospital cardiopulmonary resuscitation.
Resuscitation 2018;133:173-9.

61. Marino BS, Tabbutt $S$, MacLaren G, et al. Cardiopulmonary resuscitation in infants and children with cardiac disease: a scientific statement from the American Heart Association. Circulation 2018;137:e691-782.

62. Casadonte JR, Mazwi ML, Gambetta KE, et al. Risk factors for cardiac arrest or mechanical circulatory support in children with fulminant myocarditis. Pediatr Cardiol 2017;38:128-34.

63. Conrad SJ, Bridges BC, Kalra Y, Pietsch JB, Smith AH. Extracorporeal cardiopulmonary resuscitation among patients with structurally normal hearts. ASAIO J 2017;63:781-6.

64. Wu HP, Lin MJ, Yang WC, Wu KH, Chen CY. Predictors of extracorporeal membrane oxygenation support for children with acute myocarditis. Biomed Res Int 2017;2017:2510695.

65. Buick JE, Wallner $C_{1}$ Aickin $R$, et al. Paediatric targeted temperature management post cardiac arrest: a systematic review and meta-analysis. Resuscitation 2019;139:65-75.

66. Lin JJ, Lin CY, Hsia SH, et al. 72-h therapeutic hypothermia improves neurological outcomes in paediatric asphyxia outof-hospital cardiac arrest: an exploratory investigation. Resuscitation 2018;133:180-6.

67. Doherty DR, Parshuram CS, Gaboury I, et al. Hypothermia therapy after pediatric cardiac arrest. Circulation 2009;119:1492500.

68. Bennett $K S$, Clark AE, Meert KL, et al. Early oxygenation and ventilation measurements after pediatric cardiac arrest: lack of association with outcome. Crit Care Med 2013;41:153442.

69. Holmberg MJ, Nicholson T, Nolan JP, et al. Oxygenation and ventilation targets after cardiac arrest: a systematic review and meta-analysis. Resuscitation 2020;152:107-15.

70. Del Castillo J, Lopez-Herce J, Matamoros M, et al. Hyperoxia, hypocapnia and hypercapnia as outcome factors after cardiac arrest in children. Resuscitation 2012;83:1456-61.

71. van Zellem $L$, de Jonge $R$, van Rosmalen J, Reiss I, Tibboel $D$, Buysse $C$. High cumulative oxygen levels are associated with improved survival of children treated with mild therapeutic hypothermia after cardiac arrest. Resuscitation 2015;90:1507.

72. Lin YR, Li CJ, Wu TK, et al. Post-resuscitative clinical features in the first hour after achieving sustained ROSC predict the duration of survival in children with non-traumatic out-ofhospital cardiac arrest. Resuscitation 2010;81:410-7.

73. Lin YR, Wu HP, Chen WL, et al. Predictors of survival and neurologic outcomes in children with traumatic out-of-hospital cardiac arrest during the early postresuscitative period. J Trauma Acute Care Surg 2013;75:439-47. 
74. Young MN, Hollenbeck RD, Pollock JS, et al. Higher achieved mean arterial pressure during therapeutic hypothermia is not associated with neurologically intact survival following cardiac arrest. Resuscitation 2015;88:158-64.

75. Herman ST, Abend NS, Bleck TP, et al. Consensus statement on continuous EEG in critically ill adults and children, part I: indications. J Clin Neurophysiol 2015;32:87-95.

76. Abend NS, Topjian A, Ichord R, et al. Electroencephalographic monitoring during hypothermia after pediatric cardiac arrest. Neurology 2009;72:1931-40.

77. Topjian AA, Gutierrez-Colina AM, Sanchez SM, et al. Electrographic status epilepticus is associated with mortality and worse short-term outcome in critically ill children. Crit Care Med 2013;41:215-23.

78. Ostendorf AP, Hartman ME, Friess SH. Early electroencephalographic findings correlate with neurologic outcome in children following cardiac arrest. Pediatr Crit Care Med 2016;17:66776.

79. Brophy GM, Bell R, Claassen J, et al. Guidelines for the evaluation and management of status epilepticus. Neurocrit Care 2012;17:3-23.

80. Topjian AA, Sanchez SM, Shults J, Berg RA, Dlugos DJ, Abend NS. Early electroencephalographic background features predict outcomes in children resuscitated from cardiac arrest. Pediatr Crit Care Med 2016;17:547-57.

81. Bongiovanni F, Romagnosi F, Barbella G, et al. Standardized EEG analysis to reduce the uncertainty of outcome prognostication after cardiac arrest. Intensive Care Med 2020;46:96372.

82. Spalletti M, Carrai R, Scarpino M, et al. Single electroencephalographic patterns as specific and time-dependent indicators of good and poor outcome after cardiac arrest. Clin Neurophysiol 2016;127:2610-7.

83. Ducharme-Crevier L, Press CA, Kurz JE, Mills MG, Goldstein JL, Wainwright MS. Early presence of sleep spindles on electroencephalography is associated with good outcome after pediatric cardiac arrest. Pediatr Crit Care Med 2017;18:452-60.

84. Yoon SH, Lee EJ, Lee J, Kim MK, Ahn JG. Prognostic value of the delta neutrophil index in pediatric cardiac arrest. Sci Rep 2020;10:3497.

85. Topjian AA, Telford R, Holubkov $R$, et al. Association of early postresuscitation hypotension with survival to discharge after targeted temperature management for pediatric out-of-hospital cardiac arrest: secondary analysis of a randomized clinical trial. JAMA Pediatr 2018;172:143-53.

86. Kramer P, Miera O, Berger F, Schmitt K. Prognostic value of serum biomarkers of cerebral injury in classifying neurological outcome after paediatric resuscitation. Resuscitation 2018; 122:113-20.

87. Yacoub $M$, Birchansky $B$, Mlynash $M$, et al. The prognostic value of quantitative diffusion-weighted MRI after pediatric cardiopulmonary arrest. Resuscitation 2019;135:103-9.

88. Muhlhofer W, Szaflarski JP. Prognostic value of EEG in patients after cardiac arrest: an updated review. Curr Neurol Neurosci Rep 2018;18:16.

89. Ichord R, Silverstein FS, Slomine BS, et al. Neurologic outcomes in pediatric cardiac arrest survivors enrolled in the THAPCA trials. Neurology 2018;91:e123-31.

90. Lin JJ, Lin YJ, Hsia SH, et al. Early clinical predictors of neurological outcome in children with asphyxial out-of-hospital cardiac arrest treated with therapeutic hypothermia. Front Pediatr 2020;7:534. 